\title{
Analysis of Subdivision Automatic Control Precision Spraying
}

\author{
Minying Hu ( $\nabla$ hmy319@163.com ) \\ Hebei Agricultural University \\ Yongying Sang \\ Hebei Agricultural University \\ Jinjin Cai \\ Hebei Agricultural University \\ Shangkun Liu \\ Hebei Agricultural University \\ Degang Kong \\ Hebei Agricultural University
}

\section{Research Article}

Keywords: precision spraying, subdivision automatic control, overuse of pesticides

Posted Date: February 25th, 2021

DOI: https://doi.org/10.21203/rs.3.rs-244897/v1

License: (c) (i) This work is licensed under a Creative Commons Attribution 4.0 International License.

Read Full License 


\title{
Analysis of Subdivision Automatic Control Precision Spraying
}

\author{
Hu minying, Sang yongying, Cai jinjin, Liu shangkun, Kong degang
}

College of Mechanical and Electrical Engineering, Hebei Agricultural University, Baoding, Hebei, China

Corresponding author: Hu minying (e-mail: hmy319@163.com).

This research was financially supported by Sub-Project of National Key R\&D Program (Grant No. 2018YFD0300503-12).

\begin{abstract}
In this paper, based on the fact that is still a small peasant economy in China and there are many small plots, this article studies small and medium sprayers. In this sprayer, the subdivision precision spraying control system, designed for precision agriculture applications, was simulated by the LabVIEW software, while an experimental setup was able to measure and record during laboratory experiments. The main pipeline of sprayer chose the A and B. And the two different pipelines were set in the different target spray volume. When the theoretical spray value was kept being unchanged, the flow rate was verified with the field sprayer speed which were set by the pulse generator. With that the pressure stability test was completed. Based on the analysis and experimental results, the flow control precision is $97.03 \%$, and the pressure stability precision is $97.88 \%$, the relative average of the pulse generator is 0.05 . Finally, the subdivision system could control the flow of the two branches and was better than the traditional spray method in China, while it could achieve more precise control of spray.
\end{abstract}

INDEX TERMS precision spraying; subdivision automatic control; overuse of pesticides

\section{INTRODUCTION}

As an important means of agricultural production, the use of pesticides has played an important role in increasing China's grain output. According to statistics, it can recover 54 million tons of food losses through pesticide control every year in China[1-2] In recent years, with the continuous increase in food production, the use of pesticides in China's agricultural production has also continued to increase[3-4]. It has become the world's largest producer and consumer of pesticides in China. The total amount of pesticide use increased from 799,000 tons in 1992 to 1.783 million tons in 2015, an increase of $123.15 \%$. But at the same time, the problem of excessive application of pesticides is also more serious. At present, the overall utilization rate of pesticides in China is about $0 \%$, and about $90 \%$ of pesticides remain in the ecological environment[5-8]. Excessive use of pesticides on the one hand increases farmers' food input costs and reduces farmers' income [9], but also poses serious threats to water security, land quality, food security, and people's health[10-11]. How to reduce the excessive use of pesticides has become a key issue of urgent concern to the Chinese government. The "Action Plan for Zero Growth in Pesticide Use by 2020" issued by the Ministry of Agriculture in 2015 clearly stated: "By 2020, the pesticide utilization rate of major crops will reach more than 40\%, and strive to achieve zero growth in pesticide use." However, how to control the use of pesticides, and the current research continues. This research has great significance for the implementation of pesticide reduction in the future.

We find that farmers' production experience is an important cause of pesticide overuse, especially for small-scale farmers. Older, self-sufficient, small-scale, non-cooperative members and rice farmers with distant market towns are more likely to use pesticides based on their personal experience. In terms of pesticide use time, type, and dosage, $35.26 \%, 30.10 \%$, and $28.52 \%$ of the samples, respectively, relied on a decision based on "experience." These results will be helpful for reducing pesticides and correcting farmers' "bad habits" within agricultural ecosystems[12].

Overuse of pesticides from the application of crop protection products can cause damage to crop, ecosystems, and human health. In this report, estimations of overuse of pesticides with reference to Chinese agricultural systems are provided, based on data from literature and a modelling study. According to the optimal pesticide input amount, the overuse degree of pesticide was calculated, and the change of pesticide usage in China from 2001 to 2016 was obtained[13-15], as shown in figure 1. 


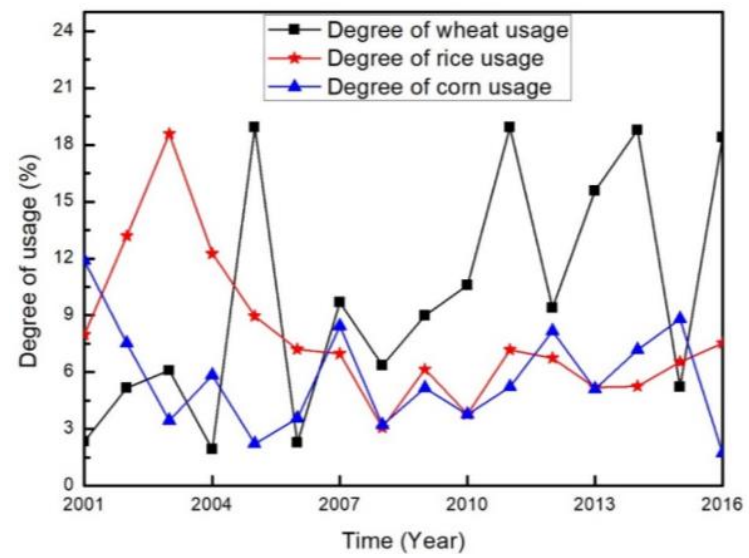

Figure 1 Changes in the degree of overuse of pesticides in China from 2001 to 2016

Figure 1 shows the time evolution of the degree of overuse of pesticides from 2001 to 2016. It can be seen that the level of overuse of pesticides in China has fluctuated. The concrete manifestation are as follows, the degree of overuse of pesticides in wheat shows a slow downward trend from 2001 to 2004. And the degree of overuse of pesticides shows a downward trend from 2011 to 2015, which may be due to China's agricultural socialization services, and the usage of rice and corn is decreased. In that stage agricultural mechanization has developed rapidly, and new varieties of with strong resistance have been selected, and the use of pesticides has decreased. In order to reduce pesticide applications in China, agricultural mechanization requires more intelligence and a precision spray system is required and improved. In addition, the planting plots in China are too small to use large-scale machinery operations on a large scale, so this project studies the precise application devices of small and mediumsized sprayers.

\section{MATERIAL, RESULTS AND DISCUSSION}

\section{A. MATERIALS}

\section{1) PRECISION SPRAYING FOR LABORATORY EXPERIMENTS}

In this experiment, a lot of equipment and supplies were used, such as water pump, filter, solenoid valve, pressure sensor flow sensor, spray pipe and so on. Hand-held GIS equipment is used for field surveys to collect pest information. Through the developed spatial data analysis software, the boundary of the experimental field was collected. And import the collected field pest data into spatial data analysis software for data processing. The working width of the test sprayer was 6 meters. The spatial data analysis software realizes the interpolation within the frame, the reclassification of the grid and the transformation of the grid. The work path is calculated according to the work width. Then three positioning points are set up in the control area on the spray bar, and it can control the spray heads in each area to realize variable spraying and calculate its control accuracy.

In this experiment, $\mathrm{CUSO}_{4}$ liquid was used instead of corn pesticides, concentration of which was the same to the corn pesticide[16-20]. This will not cause too much harm to personnel and the environment, especially repeated experiments, and, it is easy to be monitored because of the special color. So the system was established as shown in Figure 2. And the other operating parameters were shown in the table 1.

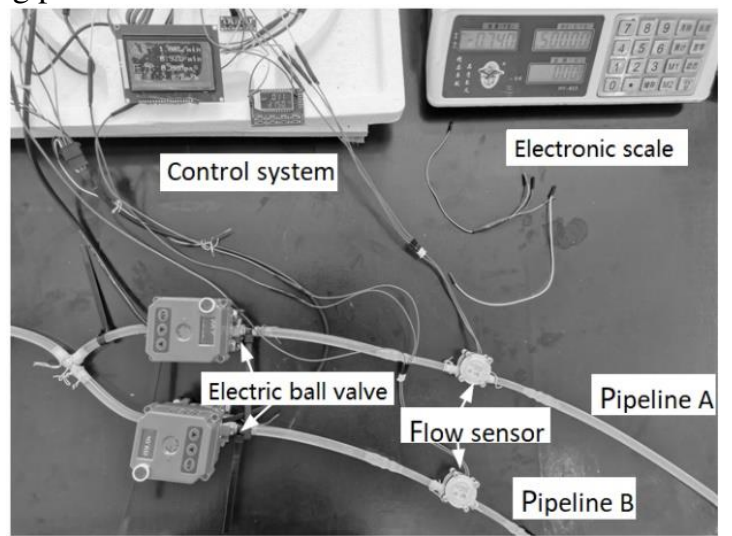

a) Diagram of shunt flow control test device

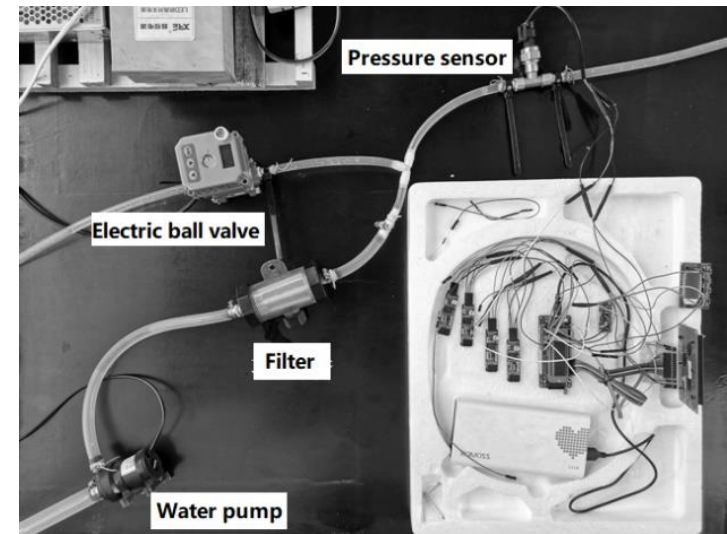

b) Pressure stability control test device 


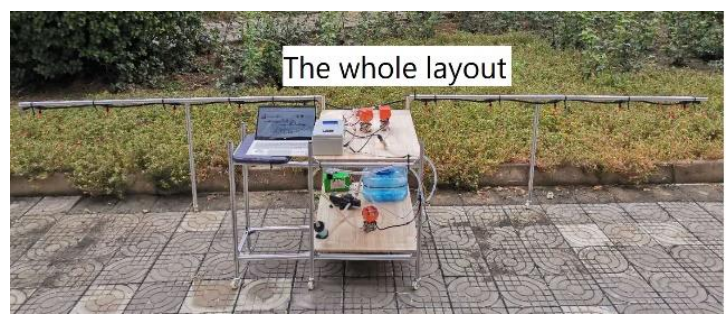

c) System Test Platform

Figure 2 Experimental layout

\begin{tabular}{llll}
\multicolumn{4}{c}{ TABLE 1 OPERATING PARAMETERS } \\
\hline $\begin{array}{l}\text { Flow range } \\
(\mathrm{L} / \mathrm{min})\end{array}$ & $\begin{array}{l}\text { Supply } \\
\text { voltage }(\mathrm{V})\end{array}$ & $\begin{array}{l}\text { Pressure } \\
(\mathrm{Mpa})\end{array}$ & $\begin{array}{l}\text { Response } \\
\text { time }(\mathrm{ms})\end{array}$ \\
\hline $0.3-6$ & $5-24$ & 0.8 & $\leq 2$ \\
\hline
\end{tabular}

\section{2) SIMULATION DATA ACQUISITION}

For data acquisition process, a graphical program was developed by using LABVIEW 8.2. The developed G-program facilitates the collection and recording of the inductive load data with the help of an STC89C52 data acquisition card to a personal computer[17-18]. The inductive force measurements were displayed both in graphical and numeric indicators on the computer screen.

\section{B. ANALOG RESULTS AND DISCUSSION}

\section{1) ANALOG DATA ACQUISITION}

The mathematical formulas are given in Equation 1, 2 and 3 [19].

$$
v=\frac{D w}{N}
$$

Where; $v$, the speed of $\operatorname{sprayer}(\mathrm{m} / \mathrm{s}) ; D$, the circumference of the wheel on which the sensor is mounted $(\mathrm{m}) ; W$, the number of pulses per second; $N$, sensor resolution(P/R).

$$
Q=\frac{q v L}{600}
$$

Where; $Q$, the theoretical flow(L/min); $q$, the spraying amount per unit area(L/ha); $L$, spraying width(m); the width of the two pipelines A and B is $3 \mathrm{~m}$ respectively.

$$
P=\left(P_{m}-P_{n}\right) \frac{P_{A I W^{-6400}}}{25600}+P_{n}
$$

Where; $P$, pressure(Kpa); $P_{m}$, the upper limit of the sensor, given by $1000 \mathrm{Kpa} ; P_{n}$, the lower limit of the sensor, set at 0 Kpa; $P_{A I W}$, sample value of pressure simulation value.

\section{2) RESULTS}

This simulation was going on as follow: a DC voltage excitation source was used to simulate the voltage value output by the pressure sensor, and transmit it to the single-chip microcomputer via the $\mathrm{i}^{2} \mathrm{C}$ bus through the $\mathrm{A} / \mathrm{D}$ conversion module, and the single-chip microcomputer will use the D/A conversion module to output the collected voltage value through the voltmeter. This contrast is shown in Figure 3 . The test data shows that the average error rate of $\mathrm{i}^{2} \mathrm{C}$ bus collection and sending data is $1 \%$, which can meet the test requirements of this design. 


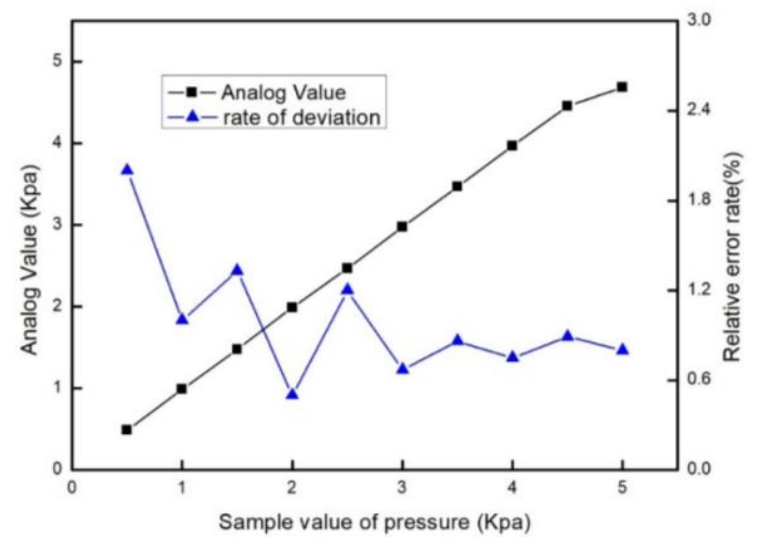

Figure 3 the comparison of analog pressure and sample value pressure

As shown in Figure 4, the LabVIEW program displays the data collected from the serial port in a waveform chart. From top to bottom, there are three parameters: flow A, flow B, and pressure. The abscissa is the time interval for collecting data, and the ordinate is the value range of each parameter. The waveform chart retains the data received last time while displaying the currently received data, so the waveform chart control can display the waveform of the input data point by point, forming a realtime curve of data changes over time.

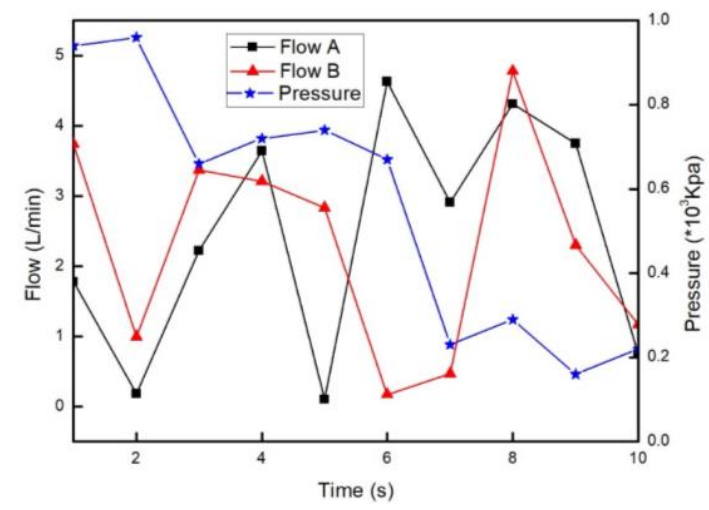

Figure 4 Three-parameter simulation curve

3) DISCUSSION

This subdivision precision spraying control and monitoring system divides the target area into two parts according to the spray range of the sprayer, and divides the spraying pipeline into two branches for separate control, which will improve the effective use of pesticides. The response effect of the simulation system is good, and the average error of the conversion of collected information is $1 \%$; Real-time display of the data collected by the serial port in the form of waveforms and numerical values, and the basic realization of user personalized storage data.

\section{EXPERIMENTAL RESULTS AND DISCUSSION}

\section{1) EXPERIMENTAL DATA ACQUISITION}

The quality of the liquid container of A and B was the same, in order to record the flow of the two pipelines separately, the measurement formulas are given in Equation 4 (Garcera, Cruz, 2017, Zhu Hang, 2010 and Sharda, A, 2015).

$$
Q_{e}=\frac{m \times 500 \times 6}{\rho t}
$$

Where; $Q_{e}$, the actual measured flow(L/min); $m$, the liquid quality $(\mathrm{g}) ; \rho$, the liquid density $(\mathrm{g} / \mathrm{L}) ; t$, monitor time, set at 10 s.

The measured flow and deviation of pipelines A and B under different theoretical flow are shown in Figure 5. 

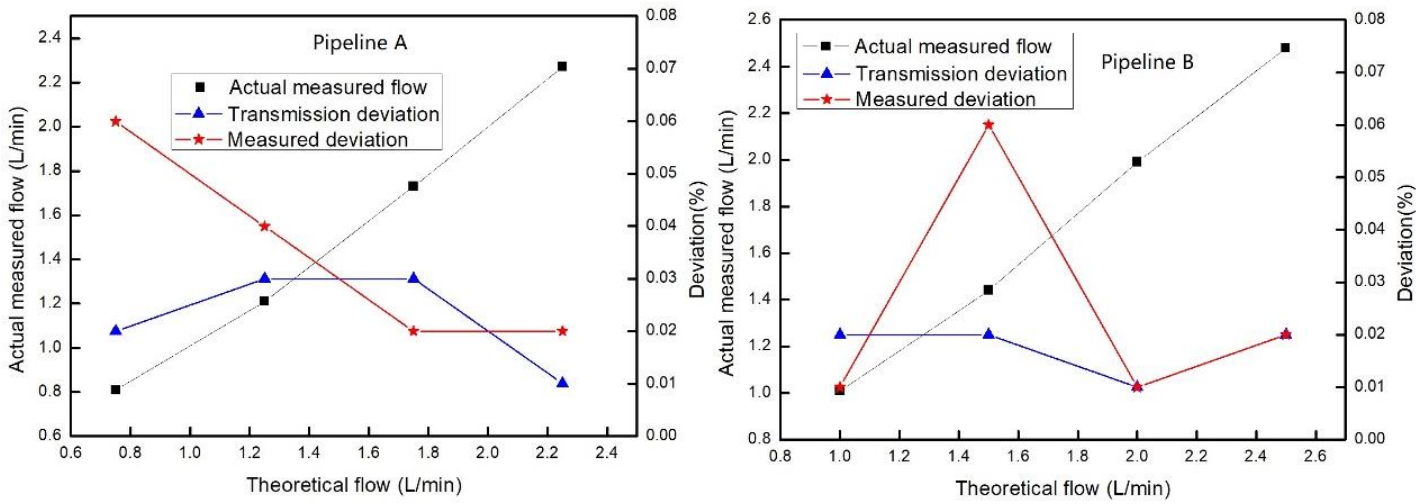

Figure 5 Experimental data of flow and deviation in pipeline $A$ and $B$

\section{2) RESULTS AND DISCUSSION}

With different theoretical flow of A and B and unchanged speed, the actual measured flow, the transmission deviation and the measurement deviation were recorded, the following results are obtained by Figure 5:

(1) The average value of the transmission deviation of the flow is 0.02 , and the transmission accuracy is $98 \%$;

(2) The average value of the measurement deviation between actual flow and theoretical flow is 0.03 , and the control accuracy is $97 \%$.

With the flow $Q=125 \mathrm{~L} / \mathrm{ha}$, changes of the flow is recorded by changing the speed. Since the setting of A and B was the same, the datum of A were recorded as shown in Figure 6.

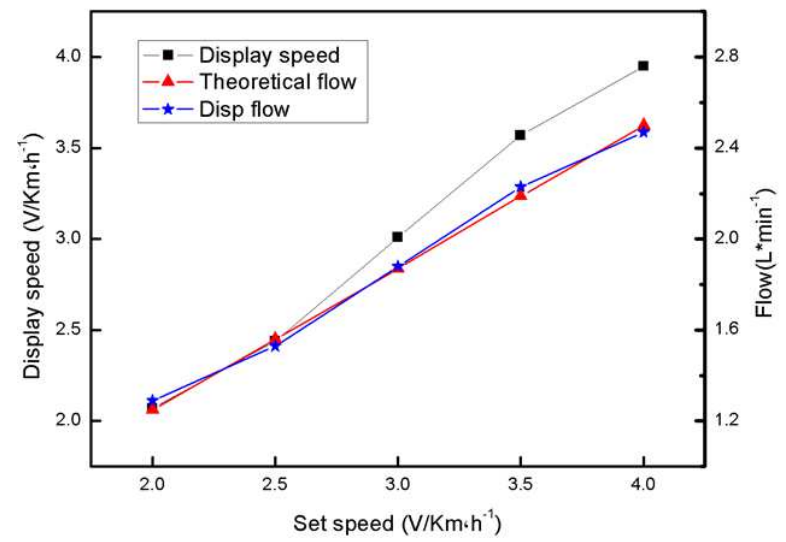

Figure 6 changes of flow

After the speed was changed, the average deviation of the actual measured flow and the theoretical flow rate was 0.03 ; as the speed increased, so did the flow in the pipeline A.

According to the pressure formula 3, the pressure stability of the pipeline was tested as shown in Figure 7.

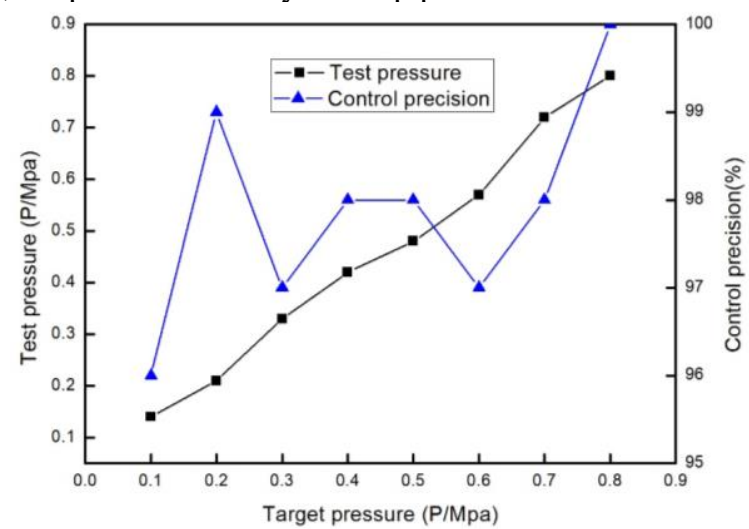

Figure 7 Control precision of the pressure stability

The theoretical pressure was given at 8 groups to verify the stability of the pressure. According to the pressure measurement value, the average value of control precision is $97.88 \%$. 
As sprayers make up the most important tool for pesticide applications in China, this study focused on control precision spraying The results presented in this report will be used to model pesticide spraying and conduct an environmental risk assessment of pesticides in Chinese agricultural systems, as part of the Sino-Dutch Pesticide Environmental Risk Assessment Project.

\section{CONCLUSIONS}

According to this research, the spray volume of the subdivision can be controlled separately. During the experiments, as the speed increases, the flow in the pipeline increases; after the speed changing, the average value of the deviation is 0.03; when the theoretical pressure increases, the electric ball valve in the return pipeline opens The pressure decreases according to a certain law; analysis and comparison of the pressure measurement and the theoretical pressure, the average value of the pressure control accuracy of this system is $97.88 \%$; realizes the separate control of the two branch flow according to the change of the target spray volume, and the control accuracy Compared with the traditional spraying method, it has been improved; the spraying range of the spraying system has been refined to achieve more precision spraying and reduce pesticide use.

The results show that the optimized formula saves calculation time while meeting the requirements of job accuracy. Finally, the overall operation of the system is tested. The test results show that the designed variable application information processing system can work normally and can complete the expected functions.

\section{REFERENCE}

[1] Liu Gang, Recovering 54 million tons of food losses every year through pesticide control in China, Pesticide market information, (23):36,(2006).

[2] Bi Sigang, Application of the technology of reducing quantity and increasing efficiency in the prevention and control of agricultural pest, AGRICULTURE AND TCHNOLOGY, 39(2): 160-162,(2019).

[3] LI Hao, LI Shiping, NAN Ling, LI Xiaoqing, A Meta-analysis of farmers' environment-friendly pesticide application behavior in China, Resources Science, 40(1):74-88,(2018).

[4] Wu X L, Zhang J B, He K, Farmers' willingness to adopt the effective pesticide spraying technology: influencing factors and group heterogeneity, Journal of China Agricultural University, 21(4): 137-148,(2016).

[5] Zhu Dian, Kong Xia, Du Jianping, Irrational Equilibrium of Farmers' Overuse of Pesticides: Evidence from Farmers in Southern Jiangsu, China. Chinese Rural Economy, (8):17-29,(2014).

[6] Wang Jianhua, Liu Zhuo, Li Xiao, Government Behavior Selection and Path Optimization in the Governance of Agricultural Product Safety Risks - Taking pesticide application in the production process of agricultural products as an example, Chinese Rural Economy, (11):54-62,(2015).

[7] Chen Zhimin(2020), Research on the Quality and Safety Risks and Governance of Agricultural Products under the Household Management Mode, AGRICULTURE AND TCHNOLOGY, 40(3): 168-169,(2020).

[8] Stifel, D and Minten, B(2008). Isolation and Agricultural Productivity, Agricultural Economics, 39(1): 1-15,(2008).

[9] Zhou Shudong, Zhang Zongyi, Pesticide application efficiency calculation, influencing factors and its relationship with pesticide productivity in farmers - improving the production function of pesticide loss control, Journal of Agrotechnical Economics, (3):4-14,(2013).

[10] Pan Dan, Yang Jiaying, Zhong Haiyan \& Guo qiaoling. Spatial-temporal analysis of pesticide overuse in major grain crops in China. Economic reference research, 2881(33): 16-23,(2018).

[11] Chen, LM; Wallhead, M; Reding, M; Horst, L; Zhu, HP, Control of Insect Pests and Diseases in an Ohio Fruit Farm with a Laser-guided Intelligent Sprayer. HORTTECHNOLOGY, 30(2): 168-175,(2020).

[12] Yanzhong Huang, Xiaofeng Luo, Lin Tang, Weizhen Yu, The power of habit: does production experience lead to pesticide overuse?, Environ Sci Pollut Res Int. Jul;27(20):25287-25296,(2020).

[13] Iost Filho, Fernando H., Heldens, Wieke B, Kong, Zhaodan, Drones: Innovative Technology for Use in Precision Pest Management, JOURNAL OF ECONOMIC ENTOMOLOGY, 113(1): 1-25,(2020).

[14] Dai Xiang, Xu, Youlin, Zheng, Jiaqiang, et al, Comparison of image-based methods for determining the inline mixing uniformity of pesticides in direct nozzle injection systems. BIOSYSTEMS ENGINEERING, 190:157-175,(2020).

[15] Morey, N. S.; Mehere, P. N.; Hedaoo, K. Agriculture drone for fertilizers and pesticides spraying, Int. J. Eng. Appl. Technol.(3):78-83,(2017).

[16] Wang, Changling; He, Xiongkui; Wang, Xiaonan; et al. Testing method and distribution characteristics of spatial pesticide spraying deposition quality balance for unmanned aerial vehicle, INTERNATIONAL JOURNAL OF AGRICULTURAL AND BIOLOGICAL ENGINEERING, 11(2):18-26,(2018).

[17] Huang, Y.; Hoffmann, W. C.; Lan, Y.; et al. DEVELOPMENT OF A SPRAY SYSTEM FOR AN UNMANNED AERIAL VEHICLE PLATFORM, APPLIED ENGINEERING IN AGRICULTURE, 25(6): 803-809,(2009). 
[18] Garcera, Cruz; Molto, Enrique; Chueca, Patricia, Spray pesticide applications in Mediterranean citrus orchards: Canopy deposition and off-target losses, SCIENCE OF THE TOTAL ENVIRONMENT, (599): 1344-1362,(2017).

[19] Zhu Hang, Lan Yubin, Wu Wenfu, et al, Development of a PWM Precision Spraying Controller for Unmanned Aerial Vehicles, JOURNAL OF BIONIC ENGINEERING, 7(3): 276-283,(2010).

[20] Sharda, A.; Fulton, J. P.; McDonald, T. P. Impact of response characteristics of an agricultural sprayer control system on nozzle flow stabilization under simulated field scenarios, 112(SI): 139-148,(2015). 


\section{Figures}

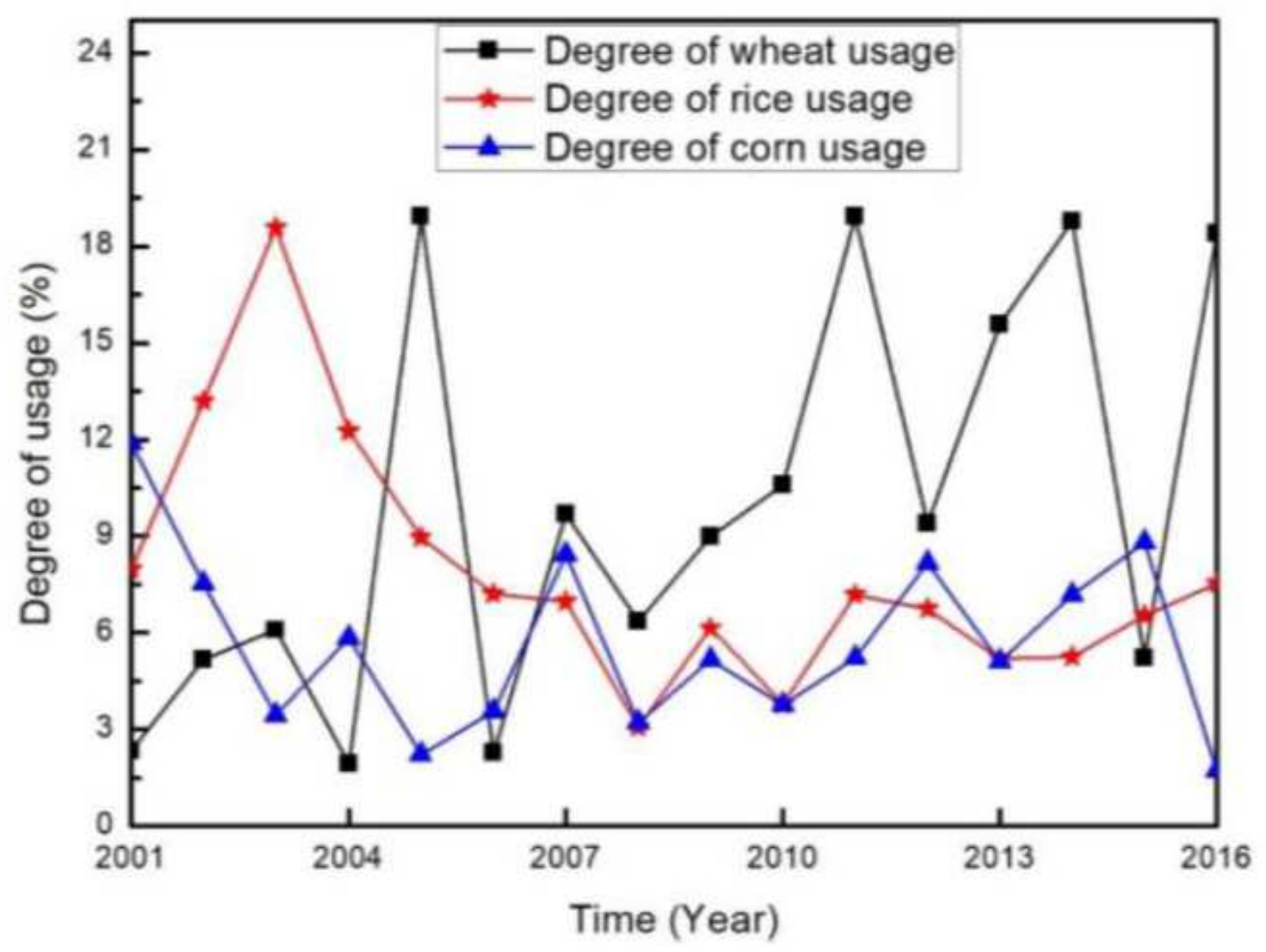

Figure 1

Changes in the degree of overuse of pesticides in China from 2001 to 2016

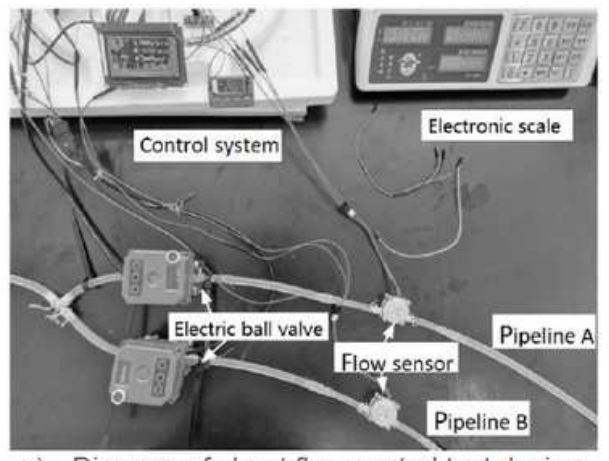

a) Diagram of shunt flow control test device

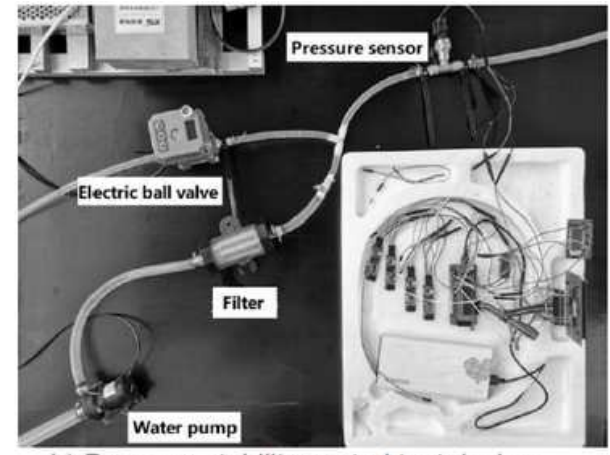

b) Pressure stability control test device

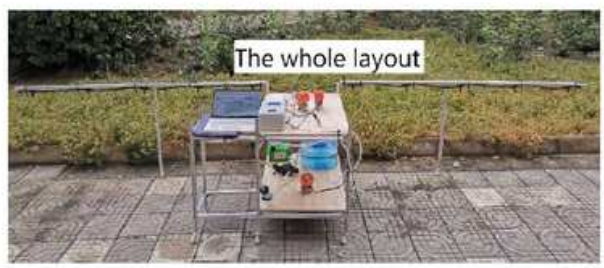

c) System Test Platform

Figure 2

Experimental layout 


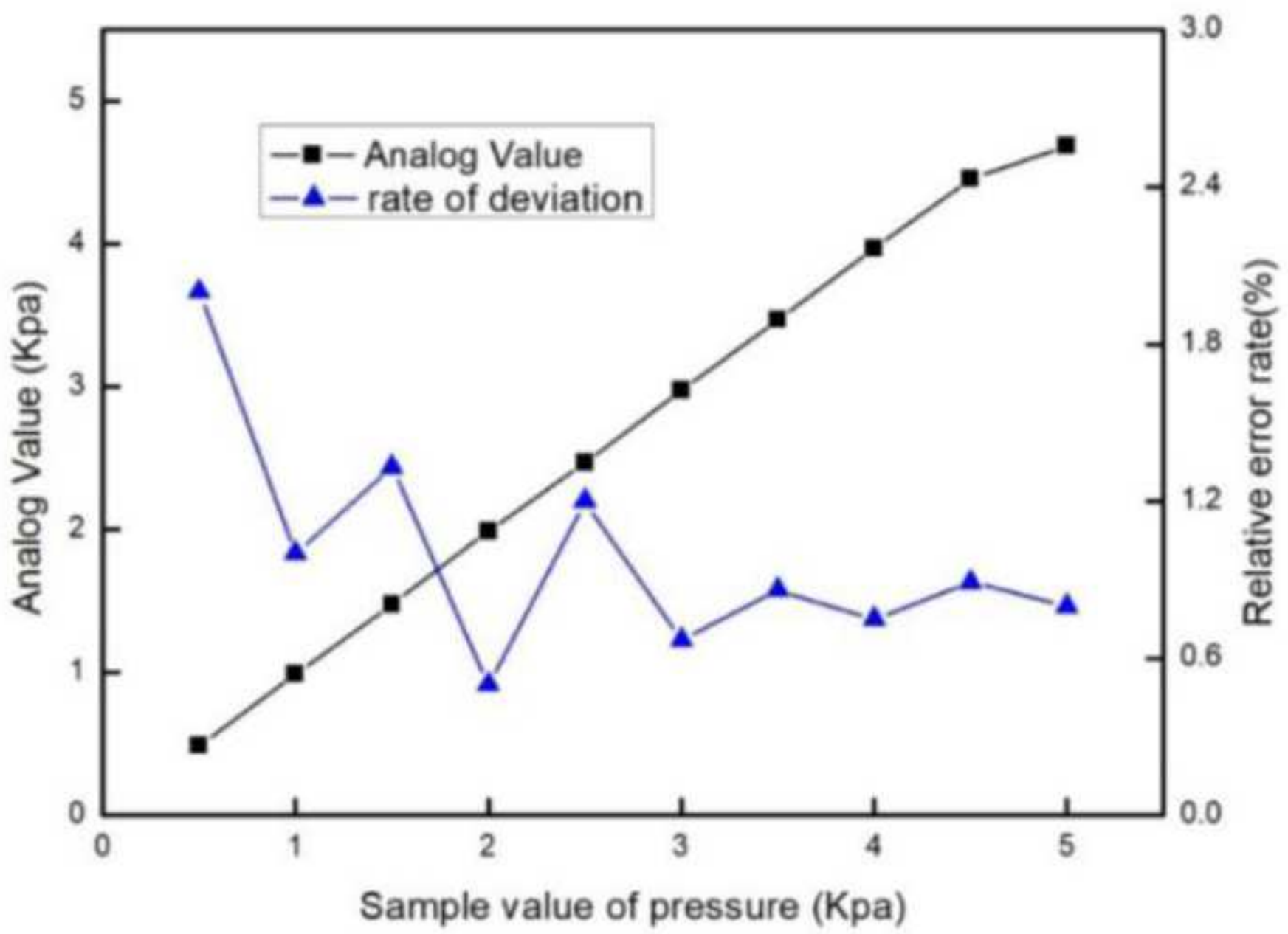

Figure 3

the comparison of analog pressure and sample value pressure 


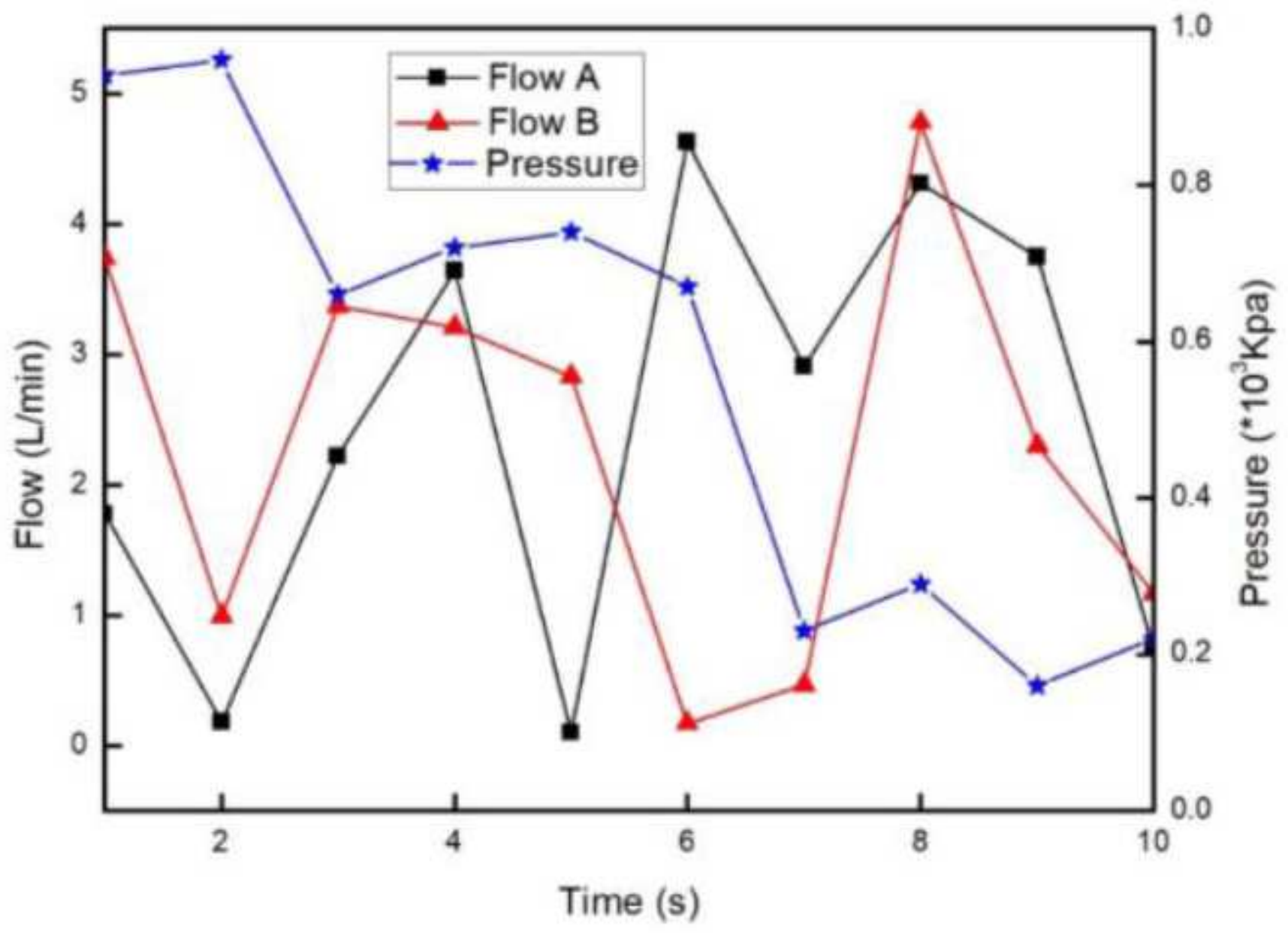

Figure 4

Three-parameter simulation curve
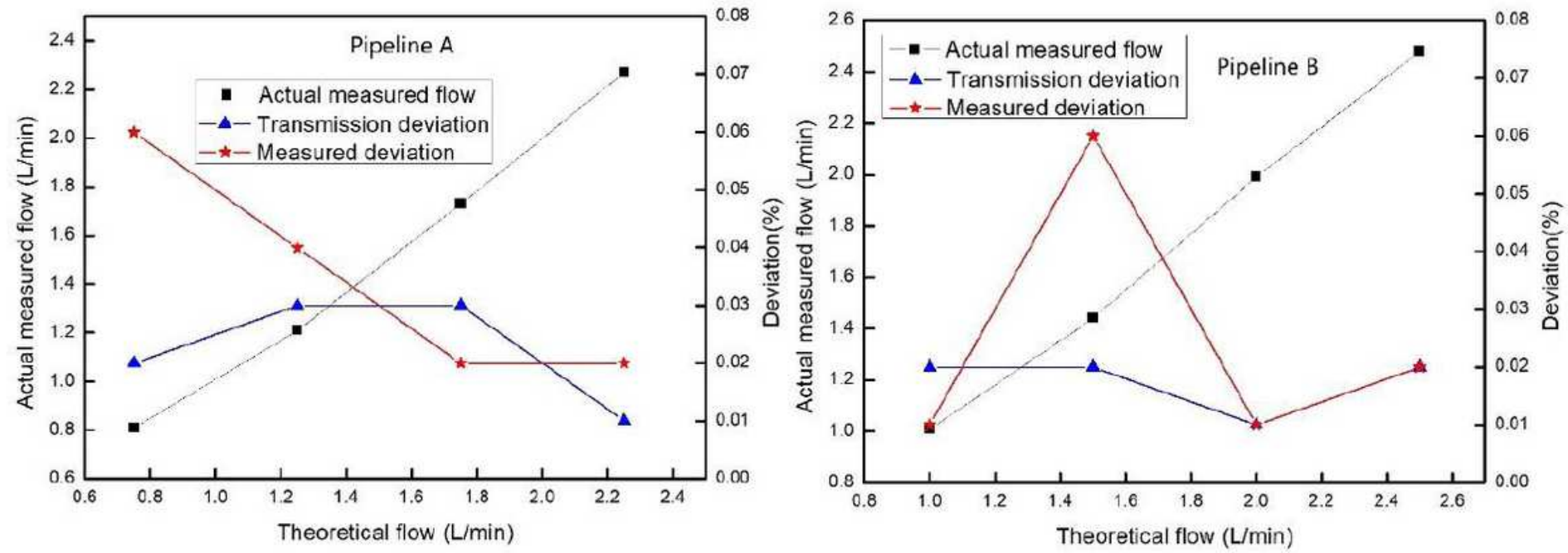

Figure 5

Experimental data of flow and deviation in pipeline $A$ and $B$ 


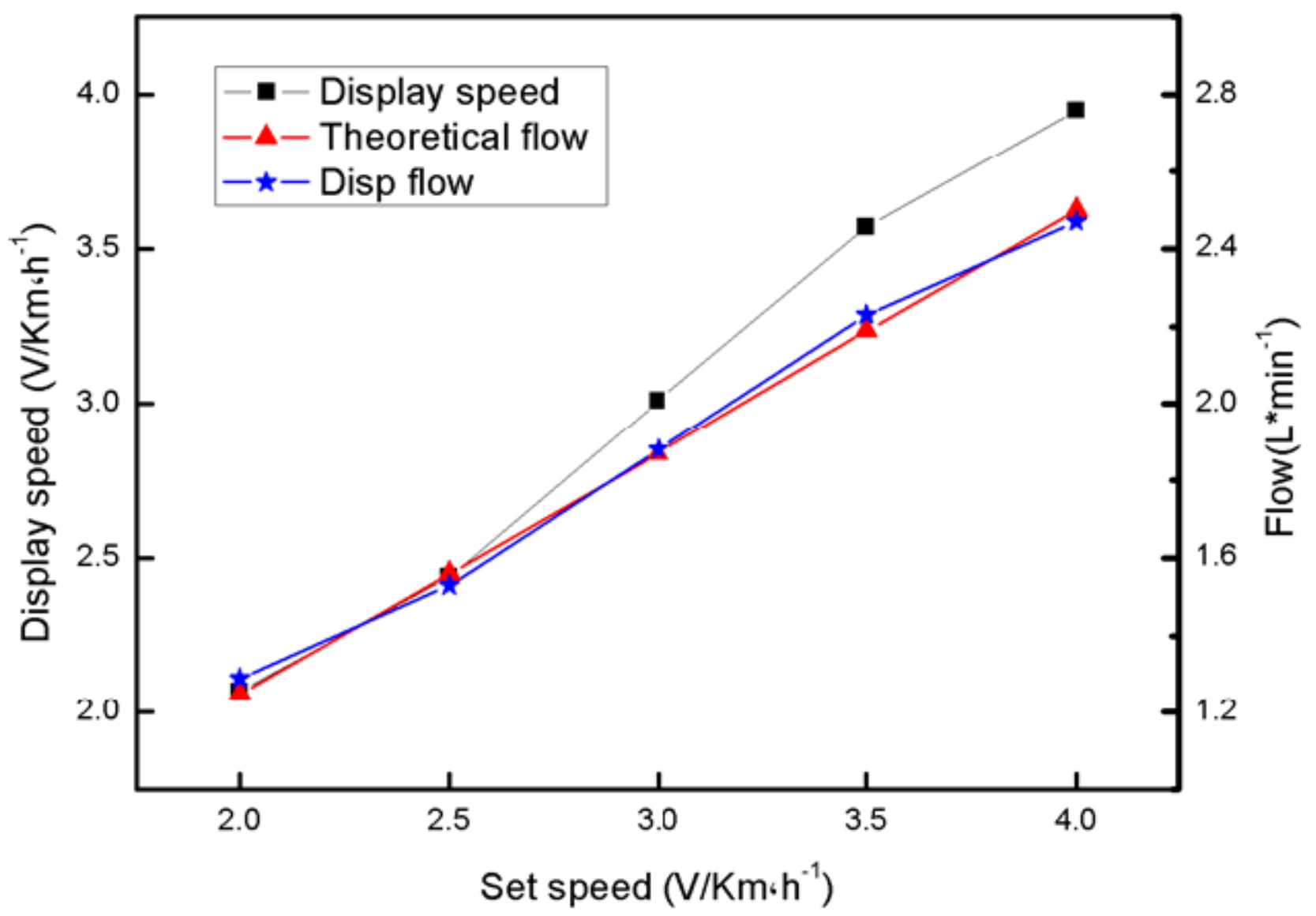

Figure 6

changes of flow 


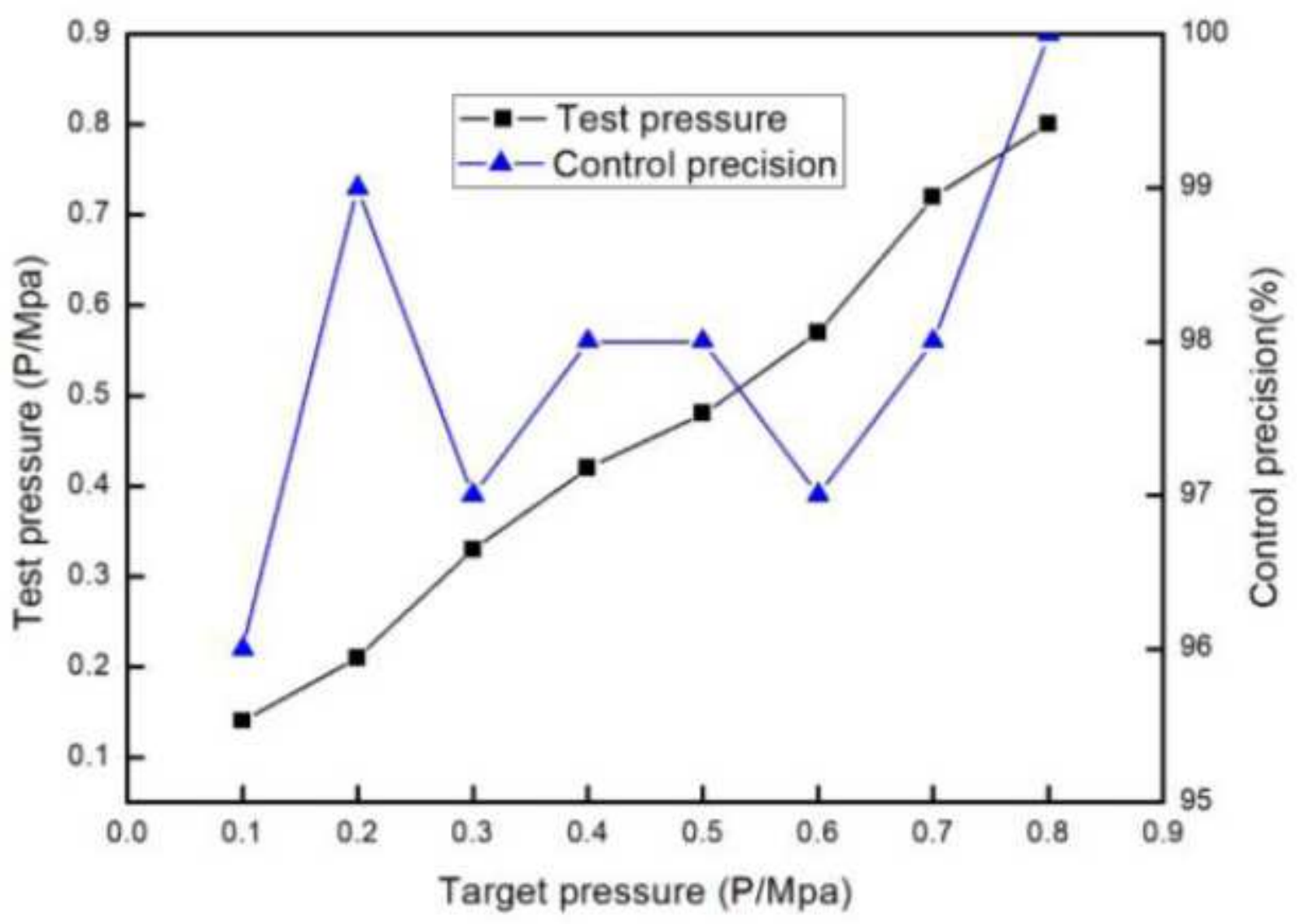

Figure 7

Control precision of the pressure stability 